\title{
Retinal vasculitis in a mother and her son with human T-lymphotropic virus type 1 associated myelopathy
}

\author{
S Hayasaka, Y Takatori, S Noda, T Setogawa, H Hayashi
}

\begin{abstract}
A 53-year-old woman had difficulty in walking, raised titres to human $T$-lymphotropic virus type 1 (HTLV-1) in serum and cerebrospinal fluid, and yellowish white retinal lesions and vasculitis in the right eye. Her 20-year-old son also had difficulty in walking, raised titres to HTLV-1 in serum and cerebrospinal fluid, and retinal vasculitis and multiple whitish vitreoretinal spots in both eyes.
\end{abstract}

Human T-lymphotropic virus type 1 (HTLV-1) causes adult T-cell leukaemia/lymphoma (ATLL) and HTLV-1 associated myelopathy (HAM). ${ }^{12}$ Both conditions are endemic. Cases of ATLL and HAM are prevalent in the Caribbean basin, south-eastern United States, Italy, subsaharan Africa, and Kyushu and Okinawa islands (south-western islands in Japan). ${ }^{34}$

Only a few investigators have reported ocular manifestations in patients with HAM living on Kyushu island. ${ }^{5-7}$ We examined two patients with HAM living in Izumo (a part of Honshu island).

\section{Case reports}

\section{CASE 1}

A 53-year-old woman complained of difficulty in walking. The disorder was slowly progressive and was followed by spastic paraparesis. Results of routine tests were negative or within the normal range. Raised titres to HTLV-1 in the serum (1:1024) and cerebrospinal fluid (1:32) were found. Myelography, computed tomogra-

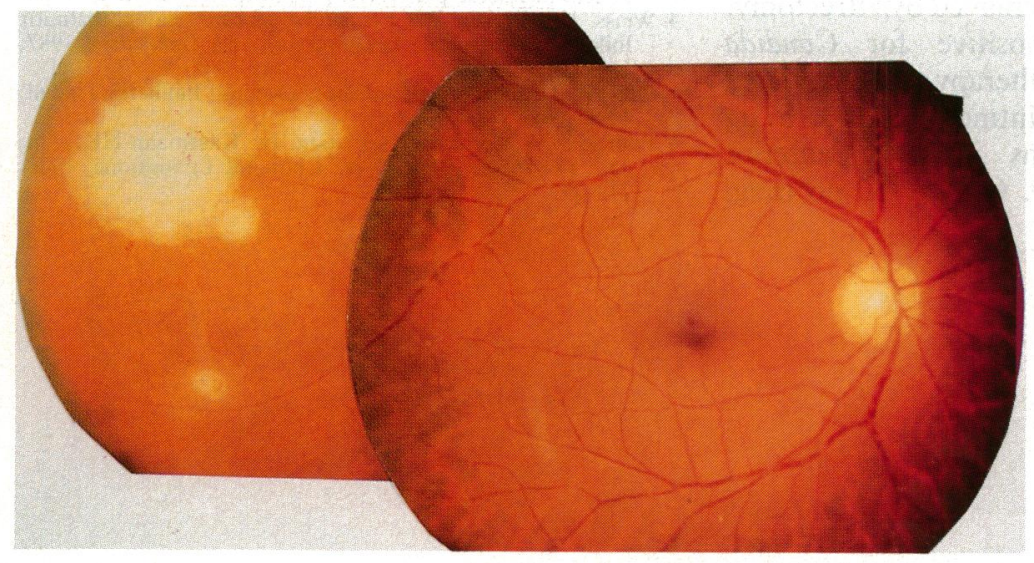

Figure 1 Case 1: whitish yellow lesions in the right temporal retina and multiple whitish dots round the retinal veins.

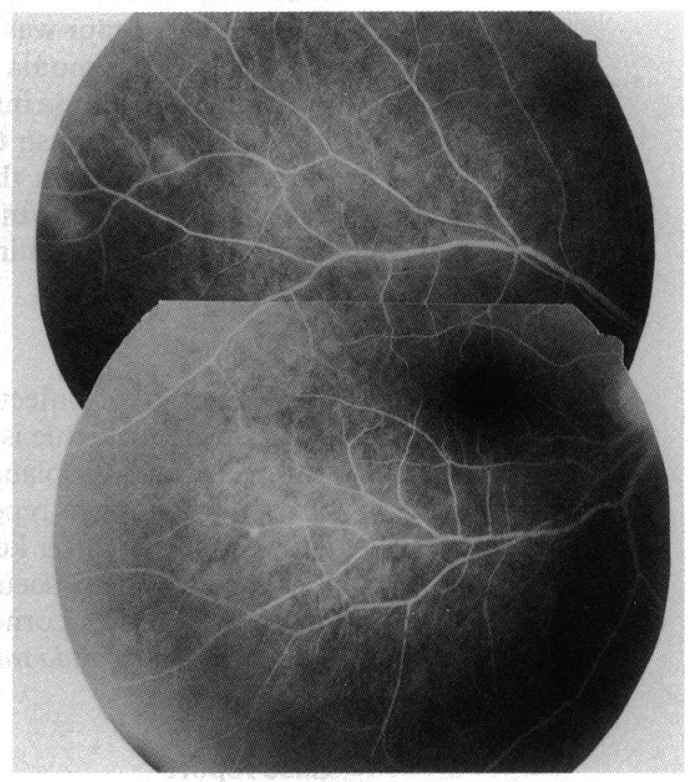

Figure 2 Case 1: fluorescein angiogram shows that the retinal venous lesions do not leak.

phy, and magnetic resonance imaging showed normal findings. The patient was treated with prednisolone, $100 \mathrm{mg} /$ day; thereafter the drug was tapered to $15 \mathrm{mg} /$ day.

In July 1990 no retinal lesions were found. In August her right visual acuity had decreased to $20 / 30$. Cells were noted in the right anterior chamber. Whitish yellow lesions were found in the right temporal fundus (Fig 1). In addition multiple whitish dots were noted round the retinal veins. Fluorescein angiography showed that the retinal venous lesions did not leak (Fig 2). Routine laboratory test results were negative or within normal range, including blood pressure; blood glucose level; serum titres to adenovirus, herpes simplex virus, cytomegalovirus, varicella zoster virus, immunodeficiency virus, and toxoplasma; angiotensin-converting enzyme level; IgG; IgM; C-reactive protein; Treponema pallidum haemagglutinin; antibody to DNA; antinuclear antibody; rheumatoid arthritis factor; tuberculin skin test; and chest $x$ ray findings. No oral aphthae or genital ulcers were noted.

In September 1990 systemic prednisolone, $100 \mathrm{mg} / \mathrm{day}$, diminished the cells in the right anterior chamber but had no effect on the yellowish white lesions or the retinal vasculitis. The prednisolone was tapered again to $15 \mathrm{mg}$ / day. In October the retinal lesions in the right eye gradually diminished. Her right visual acuity improved to $20 / 20$. 
CASE 2

The previously healthy 20-year-old son of case 1 complained of problems in walking in October 1989. The disorder was slowly progressive and was followed by spastic paraparesis. Results of routine tests were negative or within the normal range. A small number of atypical lymphocytes were found in his peripheral blood, and raised titres to HTLV-1 were noted in serum (1:8192) and cerebrospinal fluid (1:128). Myelography, computed tomography, and magnetic resonance imaging gave normal findings. No retinal lesions were found. The patient was treated with prednisolone, $50 \mathrm{mg} / \mathrm{day}$. The gait disturbance improved, and the corticosteroid was tapered.

In June 1990 the patient complained of floating spots in both eyes. The corrected visual acuity in both eyes was 20/20. The corneas and anterior chambers were transparent. Small opacities were observed in the vitreous in both eyes. Multiple whitish spots were found in the inferior retina bilaterally. Some lesions appeared around the retinal veins and arteries. Fluorescein angiography showed small amounts of leakage of dye.from the vessels. Normal findings were noted on examination of the visual fields, electroretinography, and ultrasonography in both eyes.

Laboratory test results were negative or within normal range, including blood pressure; blood glucose level; serum titres to adenovirus, herpes simplex virus, varicella-zoster virus, cytomegalovirus, human immunodeficiency virus, and toxoplasma; angiotensin-converting enzyme level; IgG; IgM; C-reactive protein; Treponema pallidum haemagglutinin; antibody to DNA; antinuclear antibody; rheumatoid arthritis factor; tuberculin skin test; and chest $x$ ray findings. No oral aphthae or genital ulcers were noted.

Although the dose of oral prednisolone was increased in July 1990, the retinal spots did not diminish, and the corticosteroid was decreased. In September the fundus lesions gradually went away.

\section{Discussion}

Our patients had myelopathy, a small number of atypical lymphocytes in the peripheral blood, and raised titres to HTLV-1 in serum and cerebrospinal fluid. A diagnosis of HAM was made. Their retinal vasculitis did not respond rapidly to corticosteroid treatment but diminished a few months later. Whitish yellow lesions in the retina of case 1 appeared to be exudate.

The ocular lesions in our patients are probably associated with HAM. Arimura $e t a l l$ described abnormal smooth pursuit movements in 11 patients with HAM. Ohba et al noted cottonwool spots in four patients with the disorder. Sasaki $e t a l$ described retinal vasculitis in three patients with HAM. The retinal lesions in our patients were similar to those described by Sasaki et al. ${ }^{7}$

Improvement of myelopathy by systemic corticosteroid therapy has been reported. ${ }^{2}$ Retinal vasculitis in three patients described by Sasaki et $a l$ did not respond to corticosteroid treatment. The retinal vasculitis in our patients did not respond rapidly to corticosteroid but diminished a few months later. This may represent either a slower delayed response to corticosteroid or could simply represent spontaneous remission despite the treatment. Mother-to-child transmission has been reported previously in HAM. ${ }^{8}$ However, we believe retinal vasculitis in a mother and her son with HAM may be rare.

The present study suggests that antibody titres to HTLV-1 in serum and cerebrospinal fluid of patients with retinal vasculitis should be examined.

1 Uchiyama T, Yodoi J, Sagara K, Takatsuki K, Uchino H. Adult T-cell leukemia: clinical and hematologic features of 16 cases. Blood 1977; 50; 481-92

2 Osame M, Usuku K, Izumo S, et al. HTLV-1 associated myelopathy: a new clinical entity. Lancet 1986; i: 1031-2. 3 Takatsuki K, Yamaguchi K, Kawano F, et al. Clinics of adult T-cell leukemia. Nippon-rinsho 1983; 41: 2659-72.

4 Osame M, Igata $A$. The history of discovery and clinicoepidemiology of HTLV-1-associated myelopathy (HAM). f fpn Soc Intern Med 1988; 77: 1343-6.

5 Arimura $Y$, Arimura $K$, Osame $M$, Igata A. Neuroophthalmological abnormalities in HTLV-1 associated myelopathy. Neuro-ophthalmology 1987; 7: 243-8.

6 Ohba N, Matsumoto M, Sameshima M, et al. Ocular manifestations in patients infected with human T-lymphotropic virus

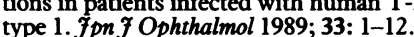

7 Sasaki K, Morooka I, Inomata H, Kashio N, Akamine T, Osame M. Retinal vasculitis in human T-lymphotropic virus type 1 associated myelopathy. $B r f$ Ophthalmol 1989; 73: type 1

8 Osame M, Igata A, Usuku K, Rosales RL, Matsumoto M. Mother-to-child transmission in HTLV-1 associated myelopathy. Lancet 1987; i: 106. 